\title{
Uniportal video-assisted thoracoscopic surgery for the treatment of thoracic emergencies
}

\author{
Marc Swierzy $^{1 \#}$, Svea Faber ${ }^{1 \#}$, Dania Nachira ${ }^{2}$, Alida Günsberg ${ }^{3}$, Jens C. Rückert ${ }^{1}$, Mahmoud Ismail $^{1}$ \\ ${ }^{1}$ Charité - Universitätsmedizin Berlin, Department of General, Visceral, Vascular and Thoracic Surgery, Campus Charité Mitte, Berlin, Germany; \\ ${ }^{2}$ Department of General Thoracic Surgery, Università Cattolica del Sacro Cuore, Fondazione Policlinico Universitario “A.Gemelli” IRCCS, Rome, \\ Italy; ${ }^{3}$ Charité - Universitätsmedizin Berlin, Department of Anesthesiology and Operative Intensive Care Medicine, Campus Charité Mitte, Berlin, \\ Germany \\ Contributions: (I) Conception and design: M Swierzy, M Ismail, S Faber; (II) Administrative support: JC Rückert; (III) Provision of study materials or \\ patients: M Ismail, M Swierzy; (IV) Collection and assembly of data: M Swierzy, S Faber, D Nachira; (V) Data analysis and interpretation: M Swierzy, \\ S Faber; (VI) Manuscript writing: All authors; (VII) Final approval of manuscript: All authors. \\ \#These authors contributed equally to this work. \\ Correspondence to: Marc Swierzy, MD. Charité - Universitätsmedizin Berlin, Department of General, Visceral, Vascular and Thoracic Surgery, \\ Campus Charité Mitte, Charitéplatz 1, 10117 Berlin, Germany. Email: marc.swierzy@klinikumevb.de.
}

Background: While video-assisted thoracoscopic surgery (VATS) is well accepted in the management of thoracic emergencies, uniportal VATS has not yet been studied for this indication. This paper reports the results of the treatment of chest trauma patients by uniportal VATS in a single center with extensive experience in uniportal VATS.

Methods: In this prospective study all patients who underwent uniportal VATS for thoracic surgical emergency cases, between 06/2012 and 09/2017, were included and the data were reviewed retrospectively.

Results: Six hundred forty-two uniportal VATS procedures were performed. Among those, 12 emergency cases could be identified. The indication was a hemothorax with active bleeding in all cases and the uniportal VATS approach was carried out after carefully evaluating all clinical factors and risks related to such a special setting. The location, extent and severity of the injuries were diagnosed and treated intraoperatively. The conversion rate was zero. The mean surgical time was 106.25 minutes [63-240], the chest tube was removed after 6.75 days in average (range, 1-25). All patients were transferred to the post anesthesia care unit (PACU) or intensive care unit (ICU) for at least one night (range, 1-25). The mean postoperative hospital stay was 10.67 days [4-26].

Conclusions: In expert hands, uniportal VATS approach seems to be a safe and feasible procedure for both, the diagnostics and management of emergency cases, such as active thoracic bleeding in cardiopulmonary stable patients.

Keywords: Uniportal video-assisted thoracoscopic surgery (uniportal VATS); trauma; hemothorax; emergency; thoracic surgery

Submitted Feb 16, 2018. Accepted for publication Aug 21, 2018.

doi: $10.21037 /$ jtd.2018.08.126

View this article at: http://dx.doi.org/10.21037/jtd.2018.08.126

\section{Introduction}

Video-assisted thoracoscopic surgery (VATS) experienced a remarkable development in the last two decades (1). In recent years, VATS has been undergoing several modifications and implementations, in particular concerning the number and location of ports, to minimize the invasiveness of the procedure. Recently published data has shown that the minimally invasive uniportal VATS is comparable to multiport VATS regarding general 
Table 1 Demographic data

\begin{tabular}{lc}
\hline Characteristics & Patients $(\mathrm{n}=12)$ \\
\hline Gender & \\
Males & 8 \\
Females & 4 \\
Age & $63.17[28-85]$ \\
\hline
\end{tabular}

complications, but seems to reduce hospital stay (2), and have a positive impact on the postoperative pain (3), even though further studies are required for definitive conclusions. Rocco and Gonzalez-Rivas were among the first clinicians who implemented this new technique $(4,5)$. Supporters of the uniportal approach emphasize the benefit of a reduced recovery time due to the less invasive character of the procedure, whereas critics argue the possibly decremented oncological outcome. Nowadays the technique is implemented in the clinical practice worldwide (6). After performing uniportal VATS for wedge resections, lobectomies and pneumonectomies, the scope of application was extended to thoracic emergency cases (7). The first report of VATS in trauma patients was described in 1976 where thoracoscopy was used as a diagnostic means (8). Later, in 1981, Jones et al. published a series of 36 trauma patients with hemothoraces who underwent emergency thoracoscopy in local anesthesia. Thoracotomy was avoided in $44 \%$ (9). VATS compared to thoracotomy in trauma patients resulted in less postoperative pain and analgesic use, a better cosmetic outcome and a more frequent complete recovery and return to normal lifestyle after surgery (10). However, reports about emergency thoracoscopic procedures are scarce in scientific literature.

In the case of hemothorax, some authors suggest the use of early VATS for the exploration and treatment of the injury (11). Indeed, different cut-offs of chest tube output are mentioned. Mahoozi et al. recommend VATS for the treatment of hemothoraces with initial chest tube outputs of more than 300 milliliters (12).

According to other authors, the mortality could be higher in patients with a total chest tube output of $1,500 \mathrm{~mL}$ within $24 \mathrm{~h}$ compared to that of patients with a chest tube output $<500 \mathrm{~mL}$. Therefore, an explorative thoracotomy is recommended when an initial output of blood between 500 and 1,500 or $>250-500 \mathrm{~mL}$ within the first $1-3 \mathrm{~h}$ is observed (13).

Other indications for an immediate emergency anterolateral thoracotomy or sternotomy are penetrating injuries, hemodynamic shock, signs of pericardial tamponade, severe bleeding, missing peripheral pulses and acute cardiac arrest (14).

The aim of this study was to evaluate the feasibility and safety of uniportal VATS for the management of emergency cases.

\section{Methods}

The uniportal VATS technique was introduced at our clinic in 2012. Since then, 642 uniportal VATS procedures have been performed. After becoming familiar with the technique and the successful application on minor procedures, the spectrum of indications was gradually extended. All uniportal VATS performed for emergency cases, between June 2012 and September 2017 were retrospectively reviewed.

The inclusion criteria were: uniportal VATS approach for the management of active bleeding after penetrating injuries or a chest-drain output of more than $250-500 \mathrm{~mL}$ of blood within the first $1-3 \mathrm{~h}$. All patients were hemodynamically stable. Two patients presented with a hemorrhagic shock, caused by an intrathoracic bleeding after thoracentesis, they were stabilized prior to the operation. A preoperative CT scan was performed in 10 cases. Two cases had a preoperative X-ray. Three patients got a chest tube preoperatively. One in the emergency room $(1,800 \mathrm{~mL} / 12 \mathrm{~h})$ and two at the intensive care unit (ICU) (1.5 and $1 \mathrm{~L}$ spontaneously).

All patients were intubated with a double-lumen tube, positioned in left lateral or right lateral position and ventilated using a single-lung ventilation during the procedure according to the side of injury. The approach was a single incision $(3-4 \mathrm{~cm})$ in the 5 th intercostal space or through the chest tube incision. A wound protector was always in place. A $30^{\circ}$ scope was applied and purposedesigned instruments with proximal and distal articulations were used. Intraoperatively, the source of bleeding was identified and treated. If necessary, lung injuries were sutured or a wedge resection was performed. At the end of the operation a chest tube $(24 \mathrm{Ch}$.) was placed. Twelve patients were included in this pilot study.

The demographic details are shown in Table 1. Preliminary results were evaluated and the outcomes in terms of mortality, conversion rate, operation time and duration of hospital and ICU stay were analyzed. In two cases (iatrogenic hemothoraces) we adjusted the duration 

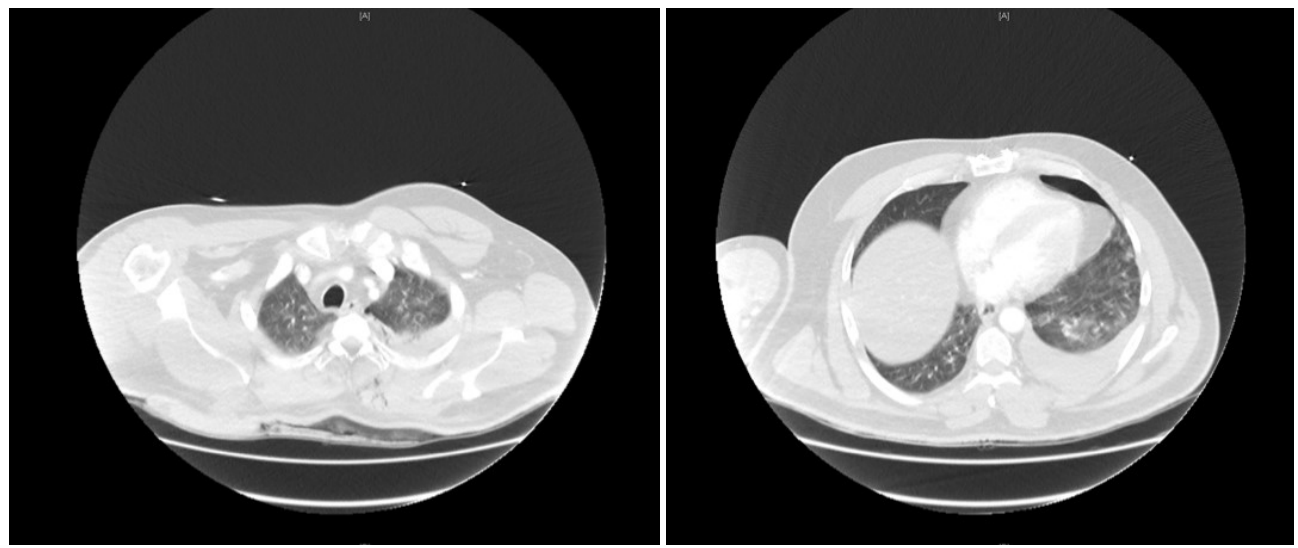

Figure 1 CT scan: male, 44 years, admission by emergency room after a stabbing, 2 thoracic stabbing injuries (right and left scapula), skin emphysema left close to 1 . dorsal left ICS, left ventral pneumothorax $(1.5 \mathrm{~cm})$, left hemothorax $(3 \mathrm{~cm})$, suspicion of an active bleeding, open fractured the scapula and olecranon, Incision injuries dorsal wrist with severing of the extensor tendons, cardiopulmonary stable, GCS 15 . ICS, intercostal space; CT, computed tomography; GCS, Glasgow Coma scale.

of "postoperative ICU and hospital stay" for the number of hospital days caused by the postoperative treatment itself. The total duration of hospitalization was prolonged due to multiple comorbidities. These two cases were long-term hospitalized preoperatively and presented with an iatrogenic hemothorax after thoracentesis. After the uniportal VATS was performed, they were admitted in thoracic surgery department until the end of postoperative treatments was finished. Since these two patients still needed to be hospitalized due to other comorbidities, the postoperative ICU and hospital stay were adjusted to the number of days until the thoracic surgical treatment was completed. The prolonged hospitalization was not caused by the surgical treatment.

The parameter "ASA-Physical Status" [American Society of Anesthesiologists (ASA)] was approximately normally distributed, as assessed by the Kolmogorow-Smirnow-test, $\mathrm{P}>0.05$ and by the Shapiro-Wilk-test, $\mathrm{P}>0.05$. Afterwards, we have analyzed possible correlations between the ASA and the post-operative hospital stay, as well as between the ASA and the mean postoperative ICU stay, as well as between the ASA and the days until the chest tube was removed, as well as between the ASA and the operation time, using the Pearson correlation. A P value $<0.05$ was considered significant.

\section{Results}

Eight (66.7\%) patients were male and four (33.3\%) female
(Table 1). The mean age was 63.17 [28-85] years (Table 1). The indications were active bleeding hemothoraces of iatrogenic origin $(\mathrm{n}=6)$, by a stabbing injury $(\mathrm{n}=1)$ (Figure 1, Table 2), by dull trauma $(\mathrm{n}=3)$, by an aspergilloma $(\mathrm{n}=1)$ and under extracorporeal membrane oxygenation (ECMO) therapy ( $\mathrm{n}=1)$.

The mean operative time was 106.25 minutes [63-240] and the chest tube was removed between the first and 25 th post-operative day (average $=6.75$ days). In two thirds of the cases the chest tube was removed during the first 5 days. The postoperative hospital stays ranged from 4 to 26 days. The mean postoperative hospital stay was 10.67 days.

All patients were transferred to the ICU after surgery, 3 (25\%) of them stayed for surveillance for only one night. Fifty-eight percent $(n=7)$ of patients stayed at ICU for 4 days or less. The average stay was 6.75 days. A significant correlation was shown between the ASA and the postoperative hospital stay $(\mathrm{r}=0.617, \mathrm{P}=0.032)$, as well as between the ASA and the mean postoperative ICU stay $(\mathrm{r}=0.812, \mathrm{P}=0.006)$ (Table 3). All other calculated correlations were not significant. There were no conversions. All cases were managed exclusively by uniportal VATS and there was no need of revision surgery. The intraoperative mortality was nil.

One patient acquired a post-operative pneumonia and one patient developed a pneumothorax. Two patients died on the 11 th and 12 th postoperative day of multi-organfailure caused by their multiple comorbidities (Table 2). The four patients with a complication were ASA 3 or 4 


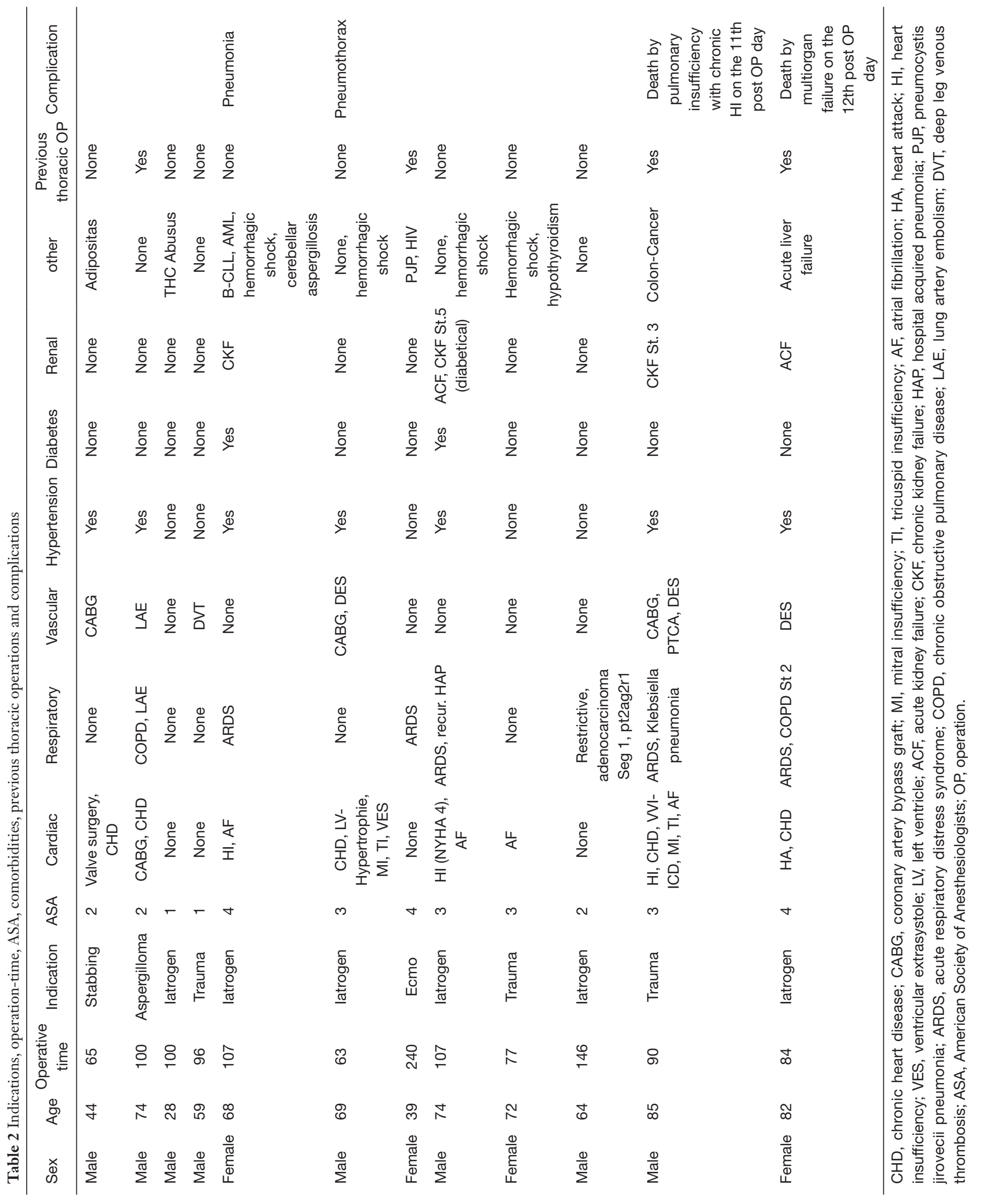


Table 3 Correlation between ASA and the mean ICU stay, Pearson correlation $=0.744(\mathrm{P}=0.006)$ and correlation between ASA and the mean postoperative hospital stay, Pearson correlation $=0.617$ $(\mathrm{P}=0.032)$

\begin{tabular}{lccc}
\hline ASA & $\mathrm{N}=12(\%)$ & $\begin{array}{r}\text { mean ICU stay } \\
\text { (days) }\end{array}$ & $\begin{array}{c}\text { Mean postoperative } \\
\text { hospital stay (days) }\end{array}$ \\
\hline 1 & $2(16.7)$ & 1 & 6 \\
2 & $3(25.0)$ & 3 & 9 \\
3 & $4(33.3)$ & 6 & 11 \\
4 & $3(25.0)$ & 16 & 16 \\
\hline
\end{tabular}

ASA, American Society of Anesthesiologists; ICU, intensive care unit.

and had multiple comorbidities, but there was no direct correlation between the two factors.

\section{Conclusions}

As stated in the German polytrauma guidelines, the standard approach for an emergency thoracotomy is anterolateral but VATS can be used for diagnostic and therapeutic indications in hemodynamically stable patients (14). VATS via single-incision has seen a huge growth over the last years. This development was initiated by Rocco and GonzalezRivas $(1,5)$. One of the main strengths of the uniportal technique is the better intraoperative view as shown by Bertolaccini et al. (15). With only one intercostal space involved and no trocars used or rib spreading, the irritation and injury of intercostal nerves is reduced or even completely avoided (16). Furthermore, the technique presents important advantages also for the surgeons, ensuring a direct view of the target and a more comfortable instrumentation and for the patient the reduction in postoperative pain and a better cosmetic outcome. Therefore, several centers have chosen uniportal VATS as their routine approach.

Due to the high mortality of thoracic trauma, fast and safe diagnostics are important. Uniportal VATS is suitable for diagnosis, inspection and exploration (17). In case of an emergency, the uniportal incision can be enlarged into a lateral thoracotomy very quickly and with less chest wall trauma compared to other, multiportal, incisions.

VATS has a favorable postoperative course, a greater patient satisfaction and a superior long-term outcome compared to open surgery in hemodynamically stable patients with blunt and penetrating chest trauma (10). Due to the small single incision uniportal VATS is also superior to other thoracic methods in the cosmetic result (18) and in postoperative mobilization (19). All these aspects are, particularly beneficial for elderly and multimorbid patients undergoing an emergency thoracic surgery.

Divisi et al. had already shown in 2004 the effectiveness for multiportal VATS approaches in a diagnostic and therapeutic role for cardiopulmonary stable patients with a chest trauma (20).

Potentially, uniportal VATS is suitable for all kinds of thoracic surgery emergency indications, such as bleeding control, stab injury, removal of foreign bodies, pneumothorax $(4,17)$.

Reasons not to perform uniportal VATS include hemodynamically instable patients, insufficient training or less experienced surgeons.

Our paper presented the preliminary results about our series of uniportal thoracic emergency cases. The main limitations of the study are: the retrospective analysis, the small sample of patients and the lack of a control group.

However according to our preliminary results, uniportal VATS seems to be a safe and feasible approach for managing thoracic emergency, in experienced hands, but further research with a larger population size is needed to confirm these findings.

\section{Acknowledgements}

None.

\section{Footnote}

Conflicts of Interest: The authors have no conflicts of interest to declare.

Ethical Statement: The study was approved by the Institutional Review Board of Charité - Universitätsmedizin Berlin.

\section{References}

1. Rocco G. Fact checking in the history of uniportal video-assisted thoracoscopic surgery. J Thorac Dis 2016;8:1849-50.

2. Akter F, Routledge T, Toufektzian L, et al. In minor and major thoracic procedures is uniport superior to multiport video-assisted thoracoscopic surgery? Interact Cardiovasc Thorac Surg 2015;20:550-5.

3. Young R, McElnay P, Leslie R, et al. Is uniport 
thoracoscopic surgery less painful than multiple port approaches? Interact Cardiovasc Thorac Surg 2015;20:409-14.

4. Rocco G, Martucci N, La Manna C, et al. Ten-year experience on 644 patients undergoing single-port (uniportal) video-assisted thoracoscopic surgery. Ann Thorac Surg 2013;96:434-8.

5. Gonzalez D, de la Torre M, Paradela M, et al. Videoassisted thoracic surgery lobectomy: 3-year initial experience with 200 cases. Eur J Cardiothorac Surg 2011;40:e21-8.

6. Guerra M, Fernandes P, Martins D, et al. Uniportal thoracoscopic lobectomy. Rev Port Cir Cardiotorac Vasc 2014;21:99-105.

7. Ismail M, Helmig $M$, Swierzy $M$, et al. Uniportal VATS: the first German experience. J Thorac Dis 2014;6:S650-5.

8. Jackson AM, Ferreira AA. Thoracoscopy as an aid to the diagnosis of diaphragmatic injury in penetrating wounds of the left lower chest: a preliminary report. Injury 1976;7:213-7.

9. Jones JW, Kitahama A, Webb WR, et al. Emergency thoracoscopy: a logical approach to chest trauma management. J Trauma 1981;21:280-4.

10. Ben-Nun A, Orlovsky M, Best LA. Video-assisted thoracoscopic surgery in the treatment of chest trauma: long-term benefit. Ann Thorac Surg 2007;83:383-7.

11. Vassiliu P, Velmahos GC, Toutouzas KG. Timing, safety, and efficacy of thoracoscopic evacuation of undrained post-traumatic hemothorax. Am Surg 2001;67:1165-9.

12. Mahoozi HR, Volmerig J, Hecker E, et al. Modern Management of Traumatic Hemothorax. J Trauma Treat 2016;5:326.

Cite this article as: Swierzy M, Faber S, Nachira D, Günsberg A, Rückert JC, Ismail M. Uniportal VATS for the treatment of thoracic emergencies. J Thorac Dis 2018;10(Suppl 31):S3720S3725. doi: $10.21037 /$ jtd.2018.08.126
13. Karmy-Jones R, Jurkovich GJ, Nathens AB, et al. Timing of urgent thoracotomy for hemorrhage after trauma: a multicenter study. Arch Surg 2001;136:513-8.

14. AMWF. S3 - Leitlinie Polytrauma / SchwerverletztenBehandlung. Deutsche Gesellschaft für Unfallchirurgie. 2017. Available online: http://www.awmf.org/uploads/tx_ szleitlinien/012-0191_S3_Polytrauma_SchwerverletztenBehandlung_2017-03.pdf

15. Bertolaccini L, Viti A, Terzi A, et al. Geometric and ergonomic characteristics of the uniportal video-assisted thoracoscopic surgery (VATS) approach. Ann Cardiothorac Surg 2016;5:118-22.

16. Tamura M, Shimizu Y, Hashizume Y. Pain following thoracoscopic surgery: retrospective analysis between single-incision and three-port video-assisted thoracoscopic surgery. J Cardiothorac Surg 2013;8:153.

17. Rocco G, Khalil M, Jutley R. Uniportal video-assisted thoracoscopic surgery wedge lung biopsy in the diagnosis of interstitial lung diseases. J Thorac Cardiovasc Surg 2005;129:947-8.

18. Yang HC, Cho S, Jheon S. Single-incision thoracoscopic surgery for primary spontaneous pneumothorax using the SILS port compared with conventional three-port surgery. Surg Endosc 2013;27:139-45.

19. Salati M, Brunelli A, Rocco G. Uniportal videoassisted thoracic surgery for diagnosis and treatment of intrathoracic conditions. Thorac Surg Clin 2008;18:30510, vii.

20. Divisi D, Battaglia C, De Berardis B, et al. Videoassisted thoracoscopy in thoracic injury: early or delayed indication? Acta Biomed 2004;75:158-63. 